\title{
Optimal central place foraging flights in relation to wind
}

\author{
Thomas Alerstam ${ }^{1}$ (D) Johan Bäckman ${ }^{1}$ Tom J. Evans²
}

Received: 28 March 2019 / Revised: 7 May 2019 / Accepted: 14 May 2019 / Published online: 3 June 2019

(c) The Author(s) 2019

\begin{abstract}
Many flying animals, like birds feeding their young, make commuting flights between a central place and foraging areas in the surroundings. Such central place foraging (CPF) represents a special case of foraging theory. We use simple geometry and trigonometry to analyse CPF flight performance (a round-trip cycle of outward flight from the central place and inward flight back along the reverse track) in relation to wind. In addition to considering the situation of a constant and uniform wind field, we take into account two factors that are likely to apply in many CPF situations under natural conditions: (a) that animals carry a load that will increase the energy expenditure during the inward flight and (b) that they may fly at different altitudes during out- and inward flights in the wind gradient above the ground or sea surface. Four main predictions emerge: (1) efficiency of CPF flights will be reduced with increasing wind speed, and foraging at the longest ranges is expected under low wind speeds. (2) A preference for CPF flights in crosswinds is expected in a constant and uniform wind field. (3) Carrying a load during the inward flight makes it optimal to fly with a small component of following winds during this flight while the outward flight will have a corresponding component of opposed winds. (4) With a steep wind gradient (e.g. over rough terrain) providing much shelter from wind at the lowest altitudes, predicted behaviour may change from crosswind preference to a preference for flights along the head/tailwind axis (at low altitude into headwinds and high altitude in tailwinds). Detailed tests of predictions for CPF flights in relation to wind will be important for understanding constraints and adaptations in animal responses to wind and for evaluating consequences of changing wind regimes in animal movement ecology.
\end{abstract}

Keywords Optimal flight $\cdot$ Wind effect on flight $\cdot$ Commuting flights $\cdot$ Central place foraging

\section{Zusammenfassung}

\section{Optimale "central place"-Nahrungsflüge im Verhältnis zum Wind.}

Viele fliegende Tiere, wie beispielsweise Vögel, die ihre Jungen füttern, unternehmen Pendelflüge zwischen einem zentralen Platz und Nahrungsgebieten in der Umgebung. Dieses sogenannte "central place foraging" (CPF) stellt einen besonderen Fall der Nahrungssuche dar. Wir nutzten einfache Geometrie und Trigonometrie, um die CPF-Flugleistung (Hinflug ausgehend von einem zentralen Punkt und Rückflug auf dem gleichen Flugweg) im Verhältnis zu Wind zu analysieren. Zusätzlich zur Betrachtung einer konstanten und uniformen Windumgebung berücksichtigten wir zwei Faktoren, die sehr wahrscheinlich in vielen CPF-Situationen unter natürlichen Bedingungen eine Rolle spielen, (a) dass Tiere eine Last tragen, die ihren Energieaufwand auf dem Rückflug erhöht und (b) dass i.e. in unterschiedlichen Höhen während der Hin- und Rückflüge im Windgradienten über der Boden- oder Meeresoberfläche fliegen können. Vier Hauptprognosen gehen daraus hervor: (1) die Effizienz von CPF-Flügen wird mit steigender Windgeschwindigkeit reduziert und die längsten Nahrungsflüge werden bei niedrigen Windgeschwindigkeiten erwartet. (2) Eine Präferenz für CPF-Flüge bei Seitenwinden wird bei konstanter und

Communicated by F. Bairlein.

Thomas Alerstam

thomas.alerstam@biol.lu.se

1 Department of Biology, Lund University, Ecology Building, 22362 Lund, Sweden

2 Marine Laboratory, Marine Scotland Science, 375 Victoria Road, Aberdeen AB11 9DB, UK 
gleichmäßiger Windumgebung erwartet. (3) Das Tragen einer Last auf einem Rückflug ist optimaler bei leichtem Rückenwind während auf dem Hinflug dann Gegenwind herrscht. (4) Bei starken Windgradienten (z. B. über unebenem Gelände), wo niedrige Flughöhen mehr Windschutz bieten, kann sich das prognostizierte Verhalten von einer Seitenwindpräferenz zu einer Bevorzugung von Flügen entlang einer Gegenwind/Rückenwindachse (bei niedriger Flughöhe zu Gegenwind, bei großen Flughöhen zu Rückenwind) ändern. Detaillierte Tests der Prognosen für CPF-Flüge im Verhältnis zum Wind sind bedeutsam für das Verständnis von Einschränkungen für und Anpassungen von Tieren an den Wind sowie für eine Bewertung der Konsequenzen sich verändernder Windregime auf die Bewegungsökologie von Tieren.

\section{List of symbols}

$a \quad$ Ratio of wind speed to the bird's airspeed (dimensionless)

$\beta \quad$ Angle of outward flight (track) direction in relation to wind $\left(\beta=0^{\circ}\right.$ due downwind and $\beta=180^{\circ}$ due upwind). The wind direction for the complementary return flight will then be $(180+\beta)=(180-\beta)^{\circ}$

$\beta_{0} \quad$ Special case of outward flight (track) direction in relation to wind, with equal ground speed at high and low altitude in the wind gradient above the ground or sea surface

$b \quad$ Flight power (energy/time) or proportionality constant relating energy to flying time

$c \quad$ Cost factor $(c>1)$ for increase in flight power when carrying a load

$D \quad$ Flight distance from central place (round-trip distance $=2 \times D$ )

$E_{\text {tot }}$ Total energy cost for round-trip flight

$E_{\text {out }}$ Energy cost for outward flight

$E_{\text {in }} \quad$ Energy cost for inward (return) flight

$f \quad$ Body frontal area

$h_{0} \quad$ Scale height indicating surface roughness in the logarithmic wind gradient above the ground or sea surface

$h_{1} \quad$ Low altitude in the wind gradient above the ground or sea surface

$h_{2} \quad$ High altitude in the wind gradient above the ground or sea surface

$k \quad$ Reduction factor $(0 \leq k<1)$ for wind speed at low relative to high altitude in the wind gradient above the ground or sea surface

$m \quad$ Total body mass

$P \quad$ Flapping flight power

$S_{\text {out }} \quad$ Ground speed on outward flight

$S_{\text {in }} \quad$ Ground speed on inward (return) flight

$T_{\text {tot }} \quad$ Total flight time for a round trip

$T_{\text {out }} \quad$ Flight time for the outward trip

$T_{\text {in }} \quad$ Flight time for the inward (return) trip

$V_{1} \quad$ Wind speed at low altitude in the wind gradient above the ground or sea surface

$V_{2} \quad$ Wind speed at high altitude in the wind gradient above the ground or sea surface
$V_{\mathrm{mp}} \quad$ Minimum power airspeed of bird (associated with minimum energy per time)

$V_{\mathrm{mr}} \quad$ Maximum range airspeed of bird (associated with minimum energy per distance)

\section{Introduction}

Many animals make foraging trips from a central place to which they return after each trip. A typical case of such central place foraging (CPF) is the feeding of young by birds making commuting flights between their nest/young and foraging areas in the surroundings. Such central place foraging serves as a basis for a classical special case of foraging theory, from which predictions about e.g. optimal prey selection, patch use, food search and load size in relation to foraging distance from the central place have been derived and tested (e.g. Orians and Pearson 1979; Schoener 1979; Stephens and Krebs 1986). Not only have foraging behaviour and food selection been analysed in birds on commuting trips but also optimal flight speeds have been analysed for birds maximizing rates of energy delivered to their young (e.g. Norberg 1981; Hedenström and Alerstam 1995; Houston 2006).

Another factor that may be expected to affect the efficiency of CPF in a profound way that has not yet been considered in central place foraging theory is the effect of wind on the pattern of commuting CPF flights. In the ideal case of a central place forager (bird, bat, insect; in this paper we refer to birds as the prime example) making commuting flights over exposed terrain or the sea, wind will have an important influence on the economy of flights, since wind speeds will often amount to a large fraction of the birds' airspeed (and sometimes even exceed the birds' airspeed in which case CPF flights will not be possible since birds cannot return to their central place heading into a wind exceeding their own airspeed). It has long been recognized that wind has a strong influence on flight and migration performance of birds, and different aspects like selectivity of winds for the flights, orientation in relation to wind (drift or compensation) and adjustment of flight speed and mode of flight relative to wind have been extensively studied (e.g. Alerstam 1979, 2011; Liechti 2006; Chapman et al. 2011; McLaren et al. 2014). 
In this study we wish to add theoretical predictions about optimal CPF flights in relation to wind. We use simple geometry and trigonometry to analyse the round-trip flight performance for the combination of an outward flight from the central place and an inward (return) flight back along the reverse track to the central place in a wind regime that remains constant during the round-trip cycle. Our analysis demonstrates that in the simplest case winds are expected to be to the general detriment of CPF flight performance which will decrease with increasing wind speed, as also demonstrated earlier by Pennycuick et al. (1984). Benefits that may be gained by a flight with wind assistance will always be associated with costs caused by opposed winds during the complementary flight. Costs will exceed benefits since the flight into opposed winds will be of a longer duration than the associated flight with following winds. We also demonstrate that, in a given wind situation, the optimal orientation of CPF flights is in crosswinds, while flights along the tail/ head wind axis are maximally unfavourable. These conclusions refer to a situation where the birds travel by continuous flapping flight. Other effects of wind may hold for birds using more complex flight behaviour involving much gliding, like seabirds using (dynamic) soaring flight over the sea waves (Furness and Bryant 1996; see "Discussion").

We extend the analysis by taking into account two factors that are likely to apply to many CPF situations under natural conditions: (1) that the bird carries a load (e.g. food for the young) on the inward flight that makes this flight more expensive with respect to flight power than the outward flight, and (2) that birds may use different wind speeds during out- and inward flights, respectively, by flying at different altitudes in the wind gradient above the ground or sea surface. In a situation of high surface roughness and a steep wind gradient (over land with a varied landscape) birds can fly sheltered from much of the wind at the lowest altitudes and their predicted behaviour may change from crosswind preference to a preference of making the commuting flights along the tail/headwind axis (because they can benefit from tailwinds and avoid much of the headwind costs by flying at low altitude in shelter from the wind on the complementary flight). However, in exposed situations like open sea or very flat and open land, crosswind preference will remain the predicted behaviour. In cases of extremely low flight close to the surface the ground effect may influence predictions (Rayner 1991; Finn et al. 2012; Johansson et al. 2018; see "Discussion").

Field observations of CPF flights under different wind conditions have been analysed in some detail for seabirds like Albatrosses (Weimerskirch et al. 2000, 2012; Wakefield et al. 2009), Shearwaters (Raymond et al. 2010; Gibb et al. 2017) and Gannets (Grémillet et al. 2004) as well as for insect-eating falcons breeding in farmland (HernándezPliego et al. 2014) and for bats (Sapir et al. 2014). These studies indicate that wind indeed is a factor of major importance, in addition to the distribution of food resources, for the directions and trajectories of CPF flights. These studies also lend support to some of the key predictions of this study (see "Discussion"). This makes detailed tests of predictions for CPF flights in relation to wind a very promising way of understanding how finely tuned birds are in their adaptations to wind conditions and how they will be affected by changing wind regimes. While the ideas in this evaluation are mostly specific to flight, some points (like the basic predictions in "Central place foraging flights in a uniform wind field" for a uniform and constant flow field) are relevant also for central place movements by swimmers in relation to water currents (cf. Chapman et al. 2011).

\section{Central place foraging flights in different wind directions}

\section{Central place foraging flights in a uniform wind field}

Consider a bird flying a straight-line distance $D$ from its central place and returning by the reverse straight-line flight path in a uniform wind field that remains the same (with respect to wind direction and speed) during the out- and inward flights. It is assumed that the bird compensates for wind drift and flies on straight-line tracks both away from and towards its central place (see comments about wind compensation/drift in the "Discussion").

The geometry of the bird's track vectors for the out- and inward flights is illustrated in Fig. 1, with wind vector of length $a$ drawn from the origin, where $a$ is the ratio of wind speed to the bird's airspeed $(0<a<1$; CPF flights become impossible with $a>1$ ). The heading vector of the bird (with airspeed $=1$ ) can be added in all different directions in relation to the wind by drawing a circle with radius $=1$ on top of the wind vector. Drawing a line through the origin at an angle $\beta$ from the wind vector to the perimeter of the circle in both directions (i.e. both angle $\beta$ and $180+\beta$ ) shows the triangles by which ground speeds (=length of track vectors) can be solved for flights in directions $\beta$ (outward flight) and $180+\beta$ (return flights) in relation to wind.

The following ground speeds $(S)$ are obtained:

$S_{\text {out }}=\sqrt{1-(a \times \sin \beta)^{2}}+a \times \cos \beta$

$S_{\text {in }}=\sqrt{1-(a \times \sin \beta)^{2}}-a \times \cos \beta$

where $a$ is wind speed relative to the bird's airspeed $(0<a<1)$ and $\beta$ is the outward track direction relative to wind (with $\beta=0^{\circ}$ being due downwind and $\beta=180^{\circ}$ due upwind). 


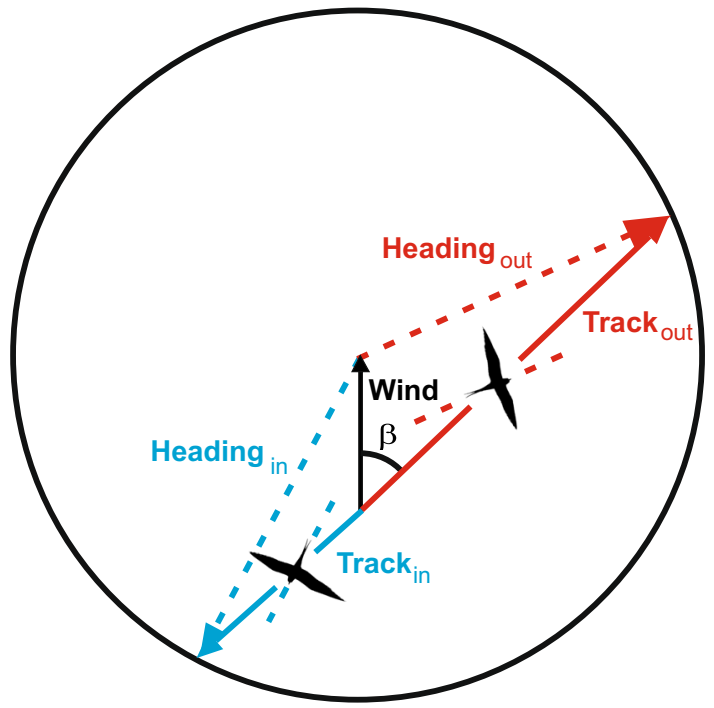

Fig. 1 Triangles of velocities for central place foraging flights in relation to wind direction. On top of the wind vector (black) a circle is drawn representing heading vectors in all different directions relative to wind. Resulting track vectors for a given wind direction $\beta$ are shown in red for the outward flight and in blue for the reverse inward flight, respectively (associated heading vectors are shown as dotted arrows). The resulting ground speeds (=length of track vector) are calculated as described in "Central place foraging flights in a uniform wind field" (Eqs. 1 and 2) (colour figure online)

The total flight time $\left(T_{\text {tot }}\right)$ for a round trip to a place at distance $D$ from the central place will be

$T_{\text {tot }}=T_{\text {out }}+T_{\text {in }}=\frac{D}{S_{\text {out }}}+\frac{D}{S_{\text {in }}}=D \times \frac{\left(S_{\text {out }}+S_{\text {in }}\right)}{S_{\text {out }} \times S_{\text {in }}}$

Dividing by the total flight time under calm conditions ( $=2 D$ with airspeed set to unity) gives the relative time cost for the combined out- and inward flights:

Relative flight time $=\frac{\left(S_{\text {out }}+S_{\text {in }}\right)}{2 \times S_{\text {out }} \times S_{\text {in }}}$

Combining Eqs. (1), (2) and (4) gives

Relative flight time $=\frac{\sqrt{1-(a \times \sin \beta)^{2}}}{\left(1-a^{2}\right)}$

This relationship is plotted in relation to $\beta$ for three cases of wind speed $(a)$ in Fig. 2a. Assuming that airspeed is fixed and flight power thus remains the same for flights under calm and various windy conditions (effects of flight speed optimization in relation to different wind conditions are considered in "Effects of flight speed optimization" in "Discussion"), the relative flight time will be equivalent to the relative energy costs for the round trip.

Another measure of the efficiency of CPF flights in different wind conditions is the relative flight range that a (a)

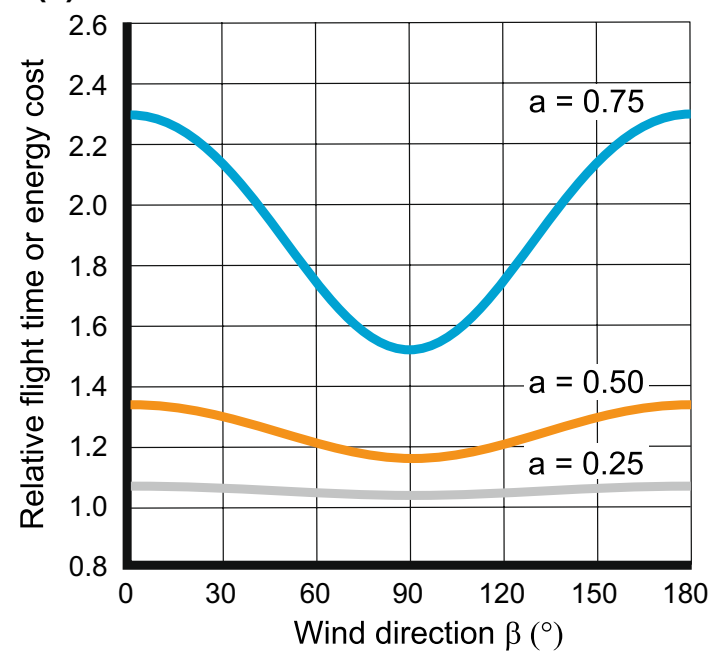

(b)

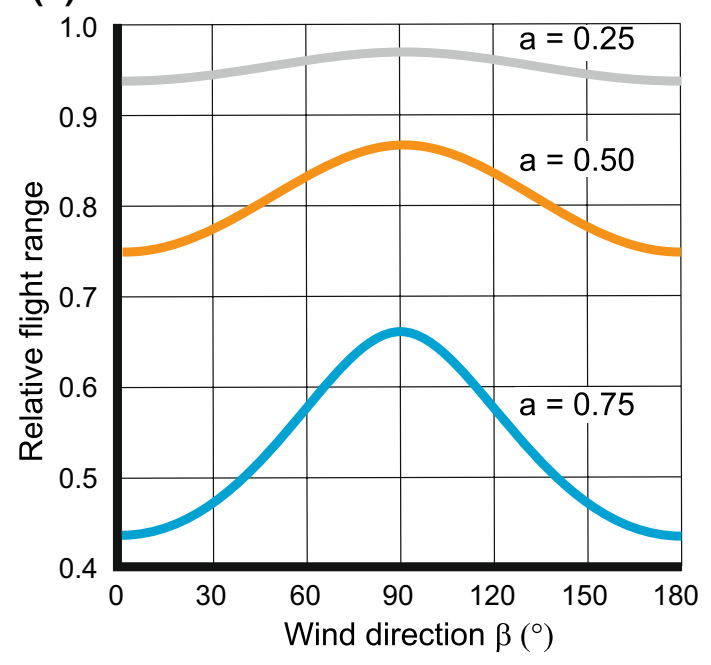

Fig. 2 a Relative time or energy costs (Eq. 4) for central place foraging flights a given distance from the origin in relation to wind direction (with outward flight in direction $\beta$ and the inward flight (180- $\beta$ ) relative to wind). The cost is expressed in relation to the round-trip time or energy cost in calm conditions and plotted in relation to wind direction for three different cases of wind speed ( $a=0.75,0.5$ and 0.25 , where $a$ is the ratio of wind speed to the bird's airspeed; see Fig. 1 and "Central place foraging flights in a uniform wind field"). Relative energy cost will be equivalent to relative flight time since airspeed is assumed to be constant (see "Effects of flight speed optimization" and Fig. 7 for the possible effects of airspeed adjustments in relation to wind conditions). b Relative range (Eq. 6) of central place foraging flights using a given amount of energy for the round trip in relation to wind direction (with outward flight in direction $\beta$ and the inward flight $(180-\beta)$ relative to wind). The range is expressed in relation to the range reached by using the same amount of time or energy in calm conditions and plotted in relation to wind direction for three different cases of wind speed $(a=0.75,0.5$ and 0.25 , where $a$ is the ratio of wind speed to the bird's airspeed; see Fig. 1 and "Central place foraging flights in a uniform wind field") 
bird can reach on a given total energy cost for the round trip. This can be obtained by solving $D$ from Eq. (3) and dividing by the range under calm conditions $\left(=T_{\text {tot }} / 2\right.$ with airspeed set to unity):

Relative flight range $=\frac{2 \times S_{\text {out }} \times S_{\text {in }}}{\left(S_{\text {out }}+S_{\text {in }}\right)}$

which is the inverse of the relative flight time (Eqs. 4 and 5). The relative range is plotted in relation to $\beta$ for three cases of wind speed $(a)$ in Fig. $2 b$.

As seen from Fig. 2, CPF becomes less efficient with increasing winds. Round-trip energy costs will increase with wind speed in relation to energy costs in calm conditions. The foraging range for a given amount of round-trip energy will become reduced with increasing wind speed. The decrease in CPF flight performance with increasing winds has been demonstrated earlier by Pennycuick et al. (1984).

This general increase in foraging costs with increasing wind speed leads to a first main prediction (a) that birds should forage at the longest ranges in calm conditions and at successively shorter ranges with increasing wind speeds. Of course, energy costs for CPF flights will be minimized with the shortest flight ranges in all wind conditions, but assuming that birds cannot forage only at the shortest distances but must, because of food depletion, distribute their food exploitation across ranges, it will be beneficial to use the days/occasions with low wind speeds for the long-ranging foraging flights and make shorter flights during windy days. The increase in energy cost for CPF flights is very substantial with moderate to strong winds, indicating a strong selection pressure for the adaption of flights in relation to wind conditions. Assuming optimal adjustment of airspeed rather than a fixed airspeed (see "Effects of flight speed optimization" in "Discussion") the differences in energy costs will become reduced but still remain significant (cf. Fig. 7).

Round-trip flight costs show a minimum for flights in crosswinds $\left(\beta=90^{\circ}\right)$ and a maximum for tail/headwind flights $\left(\beta=0^{\circ}\right.$ or $180^{\circ}$; Fig. 2). Taking the first derivative of Eq. 5 in relation to $\beta$ and setting equal to zero, there are two solutions for $\max / \min \left(\beta=0 / 180^{\circ}\right.$ and $90^{\circ}$, respectively), and the second derivative confirms that $\beta=90^{\circ}$ is associated with a minimum and $\beta=0 / 180^{\circ}$ with a maximum. This leads to a second main prediction (b) that birds are expected, other things being equal, to prefer $\mathrm{CPF}$ flights perpendicular to the prevailing wind direction. This will reduce energy costs for reaching a given range and maximize the range that can be reached on a given amount of energy (Fig. 2). This predicted preference for crosswinds should become more pronounced with increasing wind speed. This result of a distinct superiority of crosswind flights may seem counterintuitive, since you may expect birds to do best when consistently investing their heading vector aligned with their track direction. But this thought error fails to take into account that the headwind flight takes a comparatively long time because of the slow ground speed to the detriment of the resulting total round-trip performance.

\section{Effects of extra flight costs (extra load) during return flights}

Optimal CPF flights in relation to wind will be modified (to a rather small degree) when taking into account that birds will normally carry a load of food on their inward flights, which will increase the flight power by a cost factor $c(c>1)$. This means that the total energy consumption for the round trip will no longer be proportional to the total flight time according to Eq. 3, but total energy $\left(E_{\text {tot }}\right)$ for the round trip becomes

$E_{\text {tot }}=E_{\text {out }}+E_{\text {in }}=b \times \frac{D}{S_{\text {out }}}+b \times c \times \frac{D}{S_{\text {in }}}=b \times D \times \frac{\left(c \times S_{\text {out }}+S_{\text {in }}\right)}{S_{\text {out }} \times S_{\text {in }}}$

where $b$ is the proportionality constant relating energy to flying time and $c$ is the extra cost factor for the increased flight power during the inward flight (assuming equal airspeed during out- and inward flight). Dividing by $2 \times b \times D$ gives the energy consumption in relation to a round-trip flight under calm conditions (airspeed set to unity) without extra load costs:

Relative energy cost $=\frac{\left(c \times S_{\text {out }}+S_{\text {in }}\right)}{2 \times S_{\text {out }} \times S_{\text {in }}}$

What levels of extra costs $(c)$ can we expect for birds flying with a load of food? Flapping flight power $(P)$ increases with a bird's total mass $(m)$ as well as with its body frontal area $(f)$ as a result of the increase in induced and parasite drag, respectively, according to the following scaling relationship (Pennycuick 1975):

$P \propto m^{\frac{3}{2}} \times f^{\frac{1}{4}}$

An extra load will directly add to the total mass of the flying bird, but it is less clear exactly how frontal area will increase with the load, depending on whether the load is transported as ingested food in the body or in the bird's bill or talons. Still the increase in parasite drag associated with an added load is likely to be significant and raise the overall scaling exponent between flight power and mass from 1.5 (if there was no increase in parasite drag/frontal area from the extra load) to at least 1.7 when incorporating the effect of increased frontal area (corresponding to the likely effect of added fuel reserves on body frontal area; cf. Karlsson et al. 
2012). Hence, an added load of $10 \%$ or $20 \%$ (increasing mass with a factor of 1.1 or 1.2, respectively) is expected to increase flapping flight power by a factor of at least 1.2 and 1.4 , respectively.

Relative energy consumption for CPF flights is plotted in Fig. 3 (case with strong winds; $a=0.75$ ) in relation to wind direction $\beta$ for cases with cost factors $c=1.2$ and $c=1.4$ during inward flights when birds carry a load in comparison with CPF flights without effects of load (i.e. $c=1.0$ ).

The extra flight costs associated with the added load during inward flights will make it more profitable for birds to direct their outward flight into the headwind sector $\left(90^{\circ}<\beta<180^{\circ}\right)$ so that they can benefit from winds in the tailwind sector during their more costly inward flights. This will help to ameliorate the cost for transporting a load during the inward flights. Conversely, the alternative behaviour of departing in the tailwind sector and returning in headwinds will magnify the negative consequences of carrying a load during the inward flights. This asymmetry in relative energy consumption between CPF flights in tail- and headwind sectors is clearly seen from Fig. 3. The relative range on a given amount of energy for the round trip will be the inverse of Eq. 8 and show the same pattern of asymmetric advantage for outward flights into the headwind sector (not plotted).

This leads to a third prediction (c) that, taking the effects of load costs on inward flights into account, birds are expected to direct outward flights not exactly crosswind but with a small component of opposed wind (optimum $\beta$ will be $>90^{\circ}$ ) and inward flight will then have a corresponding small component of following winds. This

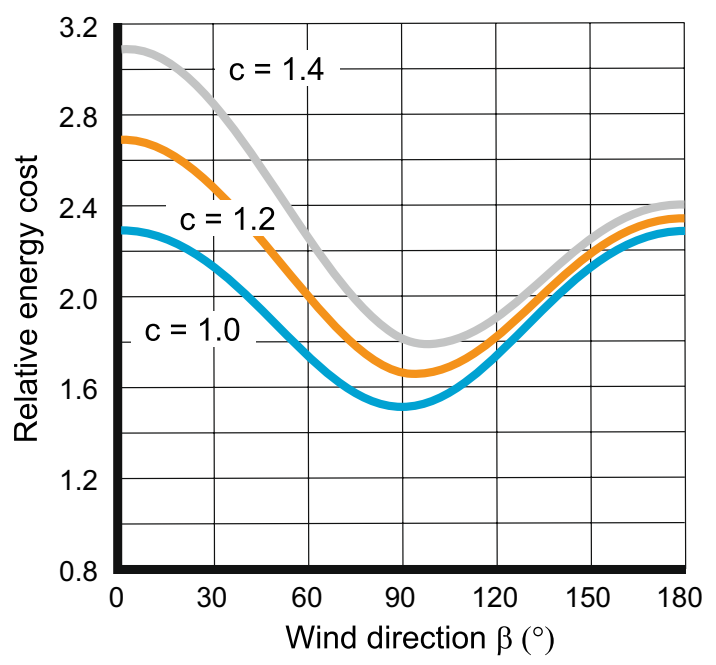

Fig. 3 Relative energy costs (Eq. 8) for central place foraging flights in relation to wind direction for cases with different cost factors $(c)$ associated with the carrying of a load on the inward flight. The graph shows a situation with strong wind speed $(a=0.75)$. See "Effects of extra flight costs (extra load) during return flights" for further explanation deviation of optimum direction from due crosswinds will be small for moderate and strong winds (with optimum $\beta$ in the range $90-110^{\circ}$ for wind speeds $a=0.75$ or 0.5 ) but will be larger for weak winds $(a=0.25)$, although such weak winds will have only a very small effect on the profitability of CPF flights in different wind directions (Fig. 2).

\section{Effects of wind speeds in surface layer}

The economy of CPF flights in different wind conditions will also be influenced by the birds changing altitude between out- and inward flights to use the most beneficial wind speeds in the wind gradient above the ground or sea surface (wind directions will differ only to a small degree in this wind gradient, and are assumed to remain constant in this analysis). Wind speed will generally become reduced with decreasing altitude according to the wind gradient equation

$\frac{V_{1}}{V_{2}}=\ln \left(\frac{h_{1}}{h_{0}}\right) / \ln \left(\frac{h_{2}}{h_{0}}\right)$

where $V_{1}$ and $V_{2}$ are wind speeds at low $\left(h_{1}\right)$ and high $\left(h_{2}\right)$ altitudes, respectively, and $h_{0}$ is a factor indicating the roughness of the surface $\left(h_{0}=0.1\right.$ corresponds to farmland, $h_{0}=0.01$ to open flat land or a very rough sea, $h_{0}=0.001$ to medium-rough sea and $h_{0}=0.0001$ to calm sea; cf. Sutton 1953; Pennycuick 1982; Glaumann and Westerberg 1988).

Calculating ratios of wind speeds at low (e.g. $\left.h_{1}=1 \mathrm{~m}\right)$ relative to high (e.g. $h_{2}=20 \mathrm{~m}$ ) altitudes shows that wind speeds may be reduced by a factor of 0.6 at low altitude $\left(=V_{1} / V_{2}\right)$ over very open land and a rough sea $\left(h_{0}=0.01\right)$ and by a factor of 0.7 over medium-rough sea $\left(h_{0}=0.001\right)$. To explore the effects of birds flying with different wind speeds on out- and inward flights at different altitudes, we considered three cases of wind speed ratios at $0.75,0.5$ and 0.25 , respectively, reflecting wind gradients ranging from open sea with a shallow wind gradient to varied terrain with much wind shelter at the lowest altitudes.

The geometry of CPF flights with two different wind speeds (at different altitudes in the surface layer) is illustrated in Fig. 4. Two wind vectors of length $a$ and $k \times a$ ( $a=$ wind speed in relation the bird's airspeed; $k=$ wind reduction factor at the low flight altitude) are drawn from the origin. On top of these two vectors the heading vector of the bird is added by drawing circles with radius $=1$ (airspeed of the bird). The bird is expected to choose the wind speed that will give the longest track vector (the highest ground speed) which will depend on the orientation of the CPF flights in relation to wind (flight direction $\beta$ in relation to wind). In the example of Fig. 4 the bird flies with stronger winds (high altitude) during the outward flight and at lower wind speeds (lower flight altitude) during the return flight. 


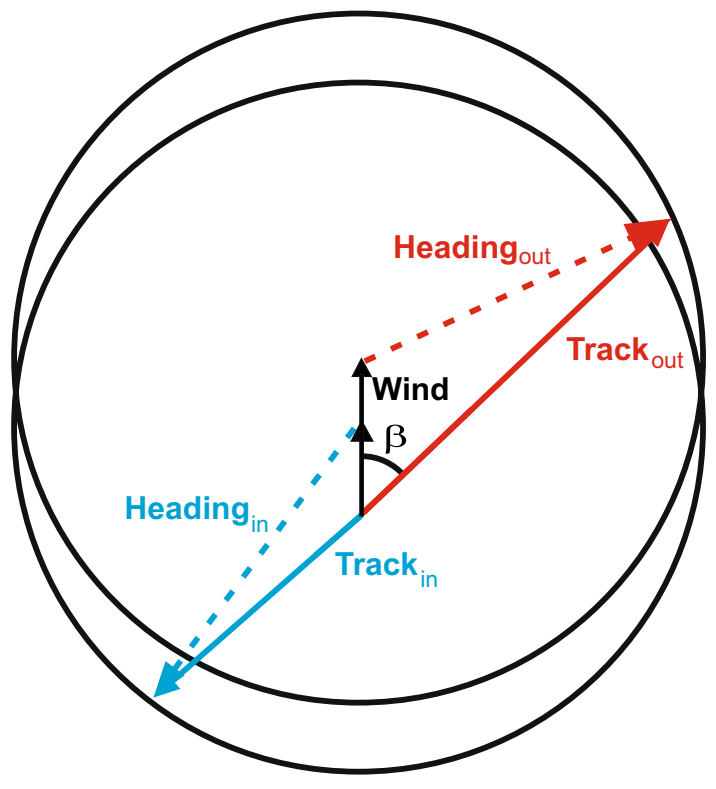

Fig. 4 Triangles of velocities for central place foraging flights in relation to wind direction in a wind gradient allowing flight at higher (long wind vector) or lower (shorter wind vector) wind speed. On top of the two wind vectors (black) circles are drawn representing heading vectors in all different directions relative to wind. CPF flights will be optimized by selecting wind speeds that give the highest ground speed, which corresponds to the stronger wind speed for the outward flight (red) and the weaker wind speed for the return flight (red) in the example illustrated. See Fig. 1 and "Effects of wind speeds in surface layer" for further explanation (colour figure online)

At a specific wind direction $\beta_{0}$ ground speeds will be equal for outward flights in the strong and reduced wind speeds (where the perimeters of the two circles intersect), and at wind direction $180-\beta_{0}$ ground speeds will be equal at the two wind speeds during the return flight, as illustrated in Fig. 5. These wind conditions are given by

$\beta_{0}=\arctan \left(\frac{\sqrt{4-a^{2} \times(1-k)^{2}}}{a \times(1+k)}\right)$

where $a$ is wind speed relative to the bird's airspeed and $k$ is the factor of wind speed reduction at low altitude in the surface layer. The flight behaviour is expected to differ between three intervals of wind direction ( $\beta$; Fig. 4$)$, such that (1) in wind directions $0 \leq \beta<\beta_{0}$ the bird is expected to fly at high altitude (wind speed $a$ ) on its outward trip and low altitude (wind speed $k \times a$ ) on the return trip, (2) in wind directions $\beta_{0} \leq \beta \leq 180-\beta_{0}$ the bird is expected to fly at low altitude (wind speed $k \times a$ ) on both out- and inward trips, and (3) in wind directions $180-\beta_{0}<\beta \leq 180$ the bird is expected to use low flight altitude on its outward trip (wind speed $k \times a$ ) and higher altitude on its return flight (wind speed $a$ ). The interval of wind directions where low

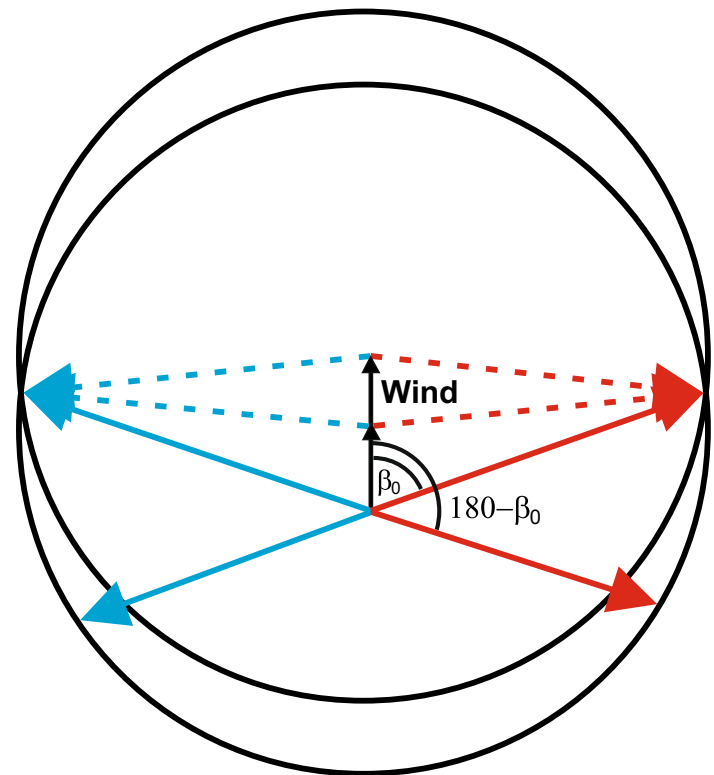

Fig. 5 At wind direction $\beta_{0}$ ground speeds will be equal for outward flights at a high and low wind speed according to the two wind vectors (black) as shown by the red track vector from the origin to the intersection of the two circles. At wind direction $\left(180-\beta_{0}\right)$ ground speeds will be equal for return flights at a high and low wind speed as shown by the blue track vector from the origin to the intersection of the two circles. These angles are calculated as described in "Effects of wind speeds in surface layer" (Eq. 11; see also Figs. 1 and 4) (colour figure online)

altitude flights are optimal on both out- and inward flights $\left(\beta_{0} \leq \beta \leq 180-\beta_{0}\right)$ becomes more restricted with decreasing wind speed (e.g. from $56.6-123.4^{\circ}$ to $77.7-102.3^{\circ}$ with wind speed decreasing from $a=0.75$ to 0.25 , given wind reduction factor $k=0.75$ ) and with stronger wind reduction factor (e.g. from $56.6-123.4^{\circ}$ to $64.0-116.0^{\circ}$ with wind reduction changing from $k=0.75$ to 0.25 , given wind speed $a=0.75$ ).

Taking these expectations into account when calculating $S_{\text {out }}$ and $S_{\text {in }}$ in the different wind direction intervals will give relative time/energy costs of CPF flights in relation to wind direction (Eq. 4) as plotted in Fig. 6 for different gradient factors in comparison with the case without a wind gradient $(k=1)$. These results show that the first and second main predictions for cases without a wind speed gradient (see "Central place foraging flights in a uniform wind field") are still likely to hold under strong winds over open sea/water and over very flat and open land where the wind gradient is less pronounced $(k=0.75)$. However, other predictions emerge for situations where the wind gradient is steeper e.g. over land with more varied terrain. If birds under such conditions adjust their out- and inward flights to altitudes/ wind speeds where ground speed is maximized, the effect of wind direction may disappear and CPF flights become almost equally profitable in all wind directions (e.g. case 


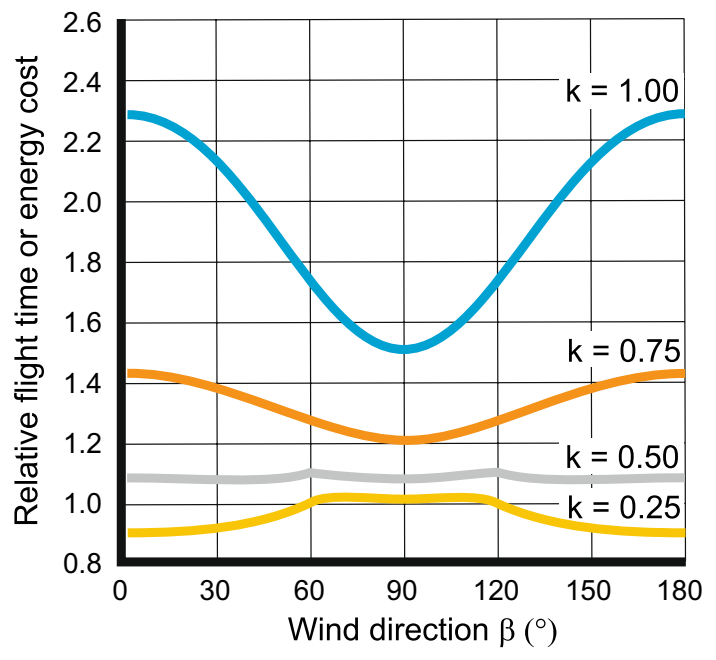

Fig. 6 Relative time or energy costs for central place foraging flights (Eq. 4 ) in relation to wind direction in a wind gradient with different ratios of wind speed at low relative to higher altitudes $(k)$. The bird is assumed to select the flight altitude giving the highest ground speed for the out- and inward flights, respectively. The graph shows a situation with strong wind speed $(a=0.75)$. Relative energy cost will be equivalent to relative flight time since airspeed is assumed to be constant (cf. "Effects of flight speed optimization"). See "Effects of wind speeds in surface layer" for further explanation

with $k=0.5$ in Fig. 6). If the birds can fly in even more pronounced low-altitude shelter from the wind (case with $k=0.25$ in Fig. 6) their optimal behaviour will change from crosswind preference to a preference to exploit due tailwinds for one of the flights (at high altitude) and avoiding most of the wind speed (at low altitude and in shelter) during the complementary flight. In such situations where birds can significantly benefit from tailwinds without having to pay a high headwind cost on the complementary flight, the overall result will be that wind will improve the efficiency of CPF flights compared to calm conditions, and flights along the tail/headwind axis will be promoted.

\section{Combined effects of extra flight costs (extra load) and changing wind speeds}

Adding the effect of extra flight costs associated with a load on the return flight (see "Effects of extra flight costs (extra load) during return flights") to the cases with surface layer (Fig. 6) will introduce an asymmetry in the relationship between CPF flight efficiency (relative energy cost) and wind direction such that outward flights in the headwind sector in combination with return flights in the tailwind sector are more favourable than the reverse behaviour. Over open sea and very open and flat land $(k=0.75, a=0.75 ; c=1.4)$ the optimal behaviour will be low altitude outward flights in crosswinds with a small component of opposed winds (optimum $\beta$ about $105^{\circ}$ ) and a low-altitude return flight in the opposite direction with a small component of following winds (see also "Effects of extra flight costs (extra load) during return flights"). Over terrain with a steeper wind gradient where birds can avoid much of the headwind flight costs $(k=0.5$ and 0.25$)$ the optimal behaviour will be low altitude outward flight straight into the headwind direction $\left(\beta=180^{\circ}\right)$ allowing the birds to return with favourable tailwinds (at higher altitudes) when they carry extra load (see also "Effects of wind speeds in surface layer").

\section{Discussion}

\section{Four main predictions}

The main predictions about optimal CPF flight behaviour in relation to wind, based on the schematic analyses above, can be summarized as follows:

1. Effect of wind speed: Wind will generally reduce efficiency of commuting flights which will promote a $\mathrm{CPF}$ behaviour of foraging at the longest ranges in calm conditions and at shorter ranges with stronger winds.

2. Crosswind preference: In a wind field that remains the same during out- and inward trips, flights in crosswinds will be optimal.

3. Effect of load: If birds carry a load on inward flights, making these flights more expensive in terms of flight power than outward flights, the optimal behaviour is a preference for flying in oblique crosswinds with a component of opposed wind during the outward flight and consequently a component of following winds during the complementary inward flight.

4. Effect of wind profile: If surface roughness and a steep wind gradient (e.g. over land with varied terrain) provide birds shelter from the wind at low altitudes, the optimal behaviour is a preference for outward flight into headwinds (without extra load) at low altitudes where wind speed is significantly reduced and return flight with tailwinds (with extra load) at higher altitudes where the birds can exploit stronger wind speeds to their benefit. Over exposed environments with a shallow wind gradient (open sea or flat open land), where preference for crosswind flights will be expected (with a small component of opposed wind during outward flight and a small component of following wind during the return flight, due to the effect of load), both out- and inward flights are predicted to occur at low altitudes where wind speeds will be slightly reduced.

It is likely that specific localization of the richest foraging sites often is an important factor to determine the dominant direction of CPF foraging flights, but in cases with a more 
uniform and wider distribution of food or with alternative rich foraging patches in different directions we expect wind to have significant effects on commuting flight patterns according to the above predictions.

\section{Effects of flight speed optimization}

In the above derivations we assumed that birds fly at a constant airspeed (and thus at constant flight power) under different wind conditions. However, this simplifying assumption is unlikely to be correct since birds are, according to flight theory, predicted to adapt their airspeed to wind conditions, depending on the primary optimization criterion for their flights (Pennycuick 1975; Liechti et al. 1994). There are also many empirical studies that provide evidence that birds adjust their airspeed in relation to winds, particularly that they tend to increase airspeed when flying into opposed winds (Hedenström et al. 2002; see also ShamounBaranes et al. 2007). Thus, we need to consider the potential effects of such wind-related airspeed adjustments (involving changes also in flight power) on our simplified derivations of central place foraging flights in relation to wind.

For central place foraging flights there are mainly three optimization criteria to consider (for explanations about the different optimal airspeeds, see Pennycuick 1975; Liechti et al. 1994; Hedenström and Alerstam 1995): (1) The birds may minimize flight power (energy cost of flight per time), in which case they should fly at $V_{\mathrm{mp}}$. $V_{\mathrm{mp}}$ is independent of wind conditions and our earlier calculations will apply. (2) The birds may minimize energy cost per distance in which case they should fly at $V_{\mathrm{mr}} V_{\mathrm{mr}}$ is dependent on winds (head/ tail as well as crosswinds; the full theoretical solution is given by Liechti et al. 1994). By assuming that the birds optimize $V_{\mathrm{mr}}$ they will minimize energy costs for the outand inward trips and thus for the total round trip. (3) The birds may also maximize energy delivery rate to their young (after accounting for the foraging time needed to satisfy their own energy requirements) in which case they should fly at a speed slightly faster than $V_{\mathrm{mr}}$ and with a closely similar dependence on wind conditions as $V_{\mathrm{mr}}$ (Norberg 1981; Hedenström and Alerstam 1995). Criteria (2) and (3) seem to be most likely to apply for central place foraging flights, although it has also been suggested that airspeeds may be generally constrained in a rather narrow interval between $V_{\mathrm{mp}}$ and $V_{\mathrm{mr}}$ (Pennycuick et al. 2013).

We used criterion (2) and the flight power model by Klein Heerenbrink et al. $(2015,2016)$, based on the most recent estimates and inferences about the different power components in bird flight (also adopting the Jackdaw Corvus monedula as example species), to calculate the total relative cost as well as the relative flight range (on a given amount of energy) for central place flights under different wind conditions (Fig. 7). For this calculation it is assumed that birds (a)

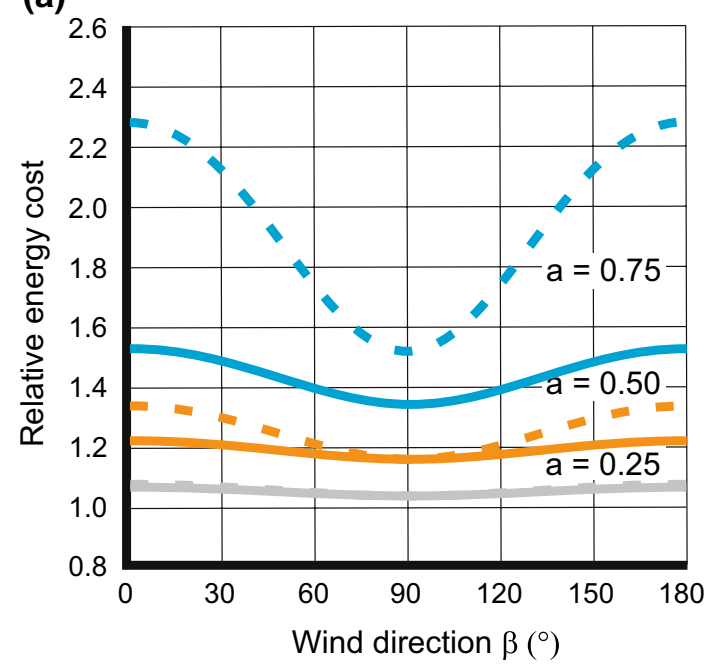

(b)

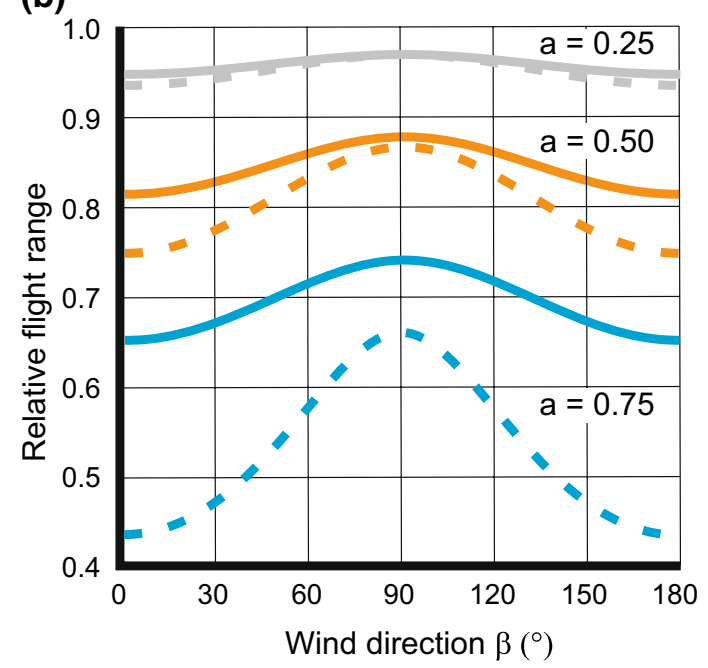

Fig. 7 a Relative energy costs (Eq. 4) for central place foraging flights a given distance from the origin in relation to wind direction (with outward flight in direction $\beta$ and the inward flight $(180-\beta)$ relative to wind) for flights with optimal airspeed adjustment (wind dependent $V_{\mathrm{mr}}$ ) for minimization of energy cost per distance (solid lines, see "Effects of flight speed optimization") or with constant airspeed (dashed lines). The cost is expressed in relation to the round-trip energy cost in calm conditions and plotted in relation to wind direction for three different cases of wind speed ( $a=0.75,0.5$ and 0.25 , where $a$ is the ratio of wind speed to the bird's optimal airspeed $V_{\mathrm{mr}}$ under calm conditions; see Fig. 1 and "Central place foraging flights in a uniform wind field"). b Relative range (Eq. 6) of central place foraging flights using a given amount of energy for the round trip in relation to wind direction (with outward flight in direction $\beta$ and the inward flight $(180-\beta)$ relative to wind) with optimal airspeed adjustment (wind dependent $V_{\mathrm{mr}}$ ) for minimization of energy cost per distance (solid lines) or with constant airspeed (dashed lines). The range is expressed in relation to the range reached by using the same amount of energy in calm conditions and plotted in relation to wind direction for three different cases of wind speed ( $a=0.75,0.5$ and 0.25 , where $a$ is the ratio of wind speed to the bird's optimal airspeed, $V_{\mathrm{mr}}$, under calm conditions; see Fig. 1 and "Central place foraging flights in a uniform wind field"). Calculations follow the R package aerodynamic model AFTP of Klein Heerenbrink, based on Klein Heerenbrink et al. $(2015,2016)$ with Jackdaw Corvus monedula as example species (calculations of chemical power) 
consistently fly at optimal $\mathrm{V}_{\mathrm{mr}}$ in relation to head-, tail- and crosswinds (Liechti et al. 1994). Comparing with the corresponding calculations assuming a fixed airspeed (Fig. 7), we find that flight speed optimization will mitigate the wind effects in an important way, but the qualitative pattern will still remain, justifying our main predictions. At wind speed $a=0.75$ the excess costs for head/tailwind flights (wind direction $\beta=0^{\circ} / 180^{\circ}$ ) compared to crosswind flights (wind direction $\beta=90^{\circ}$ ) will be reduced from $+52 \%$ to $+18 \%$, and the corresponding figures for $a=0.5$ will be a reduction from $+16 \%$ to $+9 \%$ (Fig. 7). Thus even if reduced with flight speed optimization, the extra costs still remain significant. We also noticed that $P_{\mathrm{mr}}$ for the case with fastest $V_{\mathrm{mr}}$ (headwinds with $a=0.75$ ) probably exceeded the maximum sustainable $P_{\max }$ (cf. Hedenström and Alerstam 1992). This would indicate that available muscle power may not be sufficient to optimize $V_{\mathrm{mr}}$ in such strong (and stronger) headwinds and the relative energy costs for such headwind flights will be underestimated by assuming full flight speed optimization. Calculations according to criterion (3) will show essentially the same result as for criterion (2).

We conclude that even if flight speed optimization makes the impact of wind conditions on relative energy costs less pronounced in comparison with calculations based on a fixed airspeed (Figs. 2, 3, 6), the principal qualitative conditions for our four main predictions will still hold. One should be aware that there are significant uncertainties about the power-versus-speed relationship for bird flight, not least concerning fast airspeeds, making quantitative estimates highly provisional. In addition, birds may well be constrained from attaining very fast airspeeds (optimal under strong headwinds) by their limited sustained $P_{\max }$.

\section{Predictions and field observations of CPF flights and wind}

\section{Effect of wind speed}

Whether birds vary their CPF distance in relation to wind speed has not been strictly analysed in any of the available detailed field studies of CPF flights in relation to wind (Weimerskirch et al. 2000, 2012; Grémillet et al. 2004; Wakefield et al. 2009; Hernández-Pliego et al. 2014). There are some studies that indirectly suggest that CPF distance could be reduced under stronger winds. Tree Swallows reduce provisioning rate under stronger winds (Rose 2009). Shags reduce the proportion of higher quality prey (Sandeel) provisioned to chicks under higher wind speeds (Howells et al. 2017). Similarly, Black-Legged Kittiwake and Brünnich's Guillemot adjust prey delivery rates and/or prey type depending on windspeed (Elliott et al. 2014).

However, for Albatrosses the observations indicate that stronger winds improve the efficiency of foraging flights by increasing speed and range (Weimerskirch et al. 2000, 2012), which is contrary to the first prediction in the present analysis. This clear discrepancy between predictions and observations probably stems from the fact that, for the theoretical evaluation, it was assumed that birds fly with an airspeed that is largely independent of wind (e.g. using flapping or flap-gliding flight), while Albatrosses use a mode of dynamic soaring flight extracting energy from the horizontal wind gradient over the sea (mainly by wind-shear soaring) in combination with slope soaring over the waves (Pennycuick 1982, 2002; Alerstam et al. 1993; Weimerskirch et al. 2000; Wakefield et al. 2009; Richardson 2011, 2015; Sachs 2016), where the resulting speed is a complex function of wind in a way that is not yet fully understood. For smaller seabirds and for terrestrial birds using flapping or flap-gliding as their primary modes of flight, it is much more likely that strong winds reduce the efficiency and range of commuting flights as predicted in this study, but this remains to be tested.

\section{Crosswind preference}

All the field studies mentioned above indicate that crosswind flights are of regular occurrence among CPF birds. Wandering Albatrosses Diomedea exulans breeding on the Crozet Islands in the zone of strong westerlies in the Southern Ocean preferentially departed either northeast or southeast (i.e. with following sidewinds) on their long oceanic foraging trips (Weimerskirch et al. 2000). However, these courses were associated with stereotypical looping trajectories, where the Albatrosses heading northeast changed to westerly courses when reaching the trade wind zone in the Indian Ocean before returning to Crozet on southeasterly tracks, and the Albatrosses departing towards southeast were changing to westerly courses in the zone of polar easterlies off Antarctica before returning to Crozet on northeasterly courses (Weimerskirch et al. 2000). In this way, the Albatrosses travelled with a following wind component throughout their long looping foraging flights exploiting winds in different zones to their advantage. The preference for following sidewinds may be assigned to their complex dynamic soaring behaviour in the wind speed gradient above the sea surface reaching an optimal performance level in such winds (Alerstam et al. 1993; Weimerskirch et al. 2000; Richardson 2011, 2015). CPF flights in crosswinds were regular among Cape Gannets Morus capensis in South Africa (Grémillet et al. 2004), as well as among Lesser Kestrels Falco naumanni in Spain (Hernández-Pliego et al. 2014). However, other patterns have also been reported, with Northern Gannets primarily having a cross- to tail-wind component on outward flights and a head- to cross-wind component on inward flights (Amélineau et al. 2014) and Common Guillemots primarily having tailwinds on outward flights and headwinds on inward flights (Evans et al. 2013). In the latter 
case this was likely driven by foraging destination. Whether flight direction/goal foraging area change with wind conditions remains to be critically tested (Evans et al. 2013).

The advantage of crosswind flights in comparison with flights along the tail/headwind axis would become reduced if birds fail to compensate for wind drift. If birds are subjected to partial or full wind drift their flights paths and durations to the goals (foraging patches are goals for the outward flights and the central place is the goal for the return flights) will become longer and energy costs will increase in comparison with flights along straight-line flight paths with full compensation for wind drift, as described and analysed by Alerstam (1979). Given the fact that birds have been demonstrated to achieve a high degree of compensation for wind drift in many situations (Chapman et al. 2011), as have Bumble Bees Bombus terrestris and bats been shown to fully or partially compensate for wind drift on CPF flights (Riley et al. 1999; Sapir et al. 2014), it seems reasonable to assume that CPF flights in crosswinds follow rather straight tracks without strong effects of wind drift.

\section{Effect of load}

The study of Cape Gannets provides an interesting support for the influence of load on CPF flight behaviour. The Gannets favoured foraging destinations to the south of their breeding colonies, towards which the birds departed into opposed winds in the morning. They returned with their loads of food for the young and with assistance from following winds later the same day (Grémillet et al. 2004). The advantage of this strategy was enhanced by the fact that the coastal winds were increasing through the day, so that opposed wind speeds in the morning were low but assisting winds later during the day were stronger.

One should notice that the assumption of an extra load leading to increased flight costs may not hold for birds predominantly using soaring flight (like dynamic soaring over the sea or thermal soaring over land). For such soaring flight added load may not affect flight performance very much or may even improve it depending on environmental soaring conditions (Pennycuick 1975; Alerstam 2000; Weimerskirch et al. 2012).

\section{Effect of wind profile}

There are no studies of possible differential selection of altitude and wind speed in the wind gradient above the surface between out- and inward CPF flights, so these predictions remain fully open to new tests. The case of the Cape Gannet exploiting temporal differences in wind speed by heading out into headwinds in the morning and returning with stronger tailwind later in the day makes it tempting to believe that birds also exploit spatial differences in wind speed at different altitudes in the wind gradient above the sea or ground. However, for many procellariform species that use dynamic soaring or use other complex soaring behaviour over the sea waves (Furness and Bryant 1996; Spivey et al. 2014; Gibb et al. 2017), the predictions about different flight altitudes on out- versus inward flights do not apply. These predictions apply only to birds that consistently fly at rather precise altitude levels, by flapping or flap-gliding flight. Even for birds flying by continuous flapping, flight predictions may be affected for rare cases where birds fly at such extremely low altitude over the sea or ground surface that the aerodynamic ground effect must be taken into account (Rayner 1991; Finn et al. 2012; Johansson et al. 2018).

Commuting flights by birds and other flying animals in a CPF situation represent a promising case for analysing and understanding constraints and adaptations in the birds' responses to wind. This study has provided some first schematic predictions that may be tested by detailed tracking studies of CPF flights in different wind fields over exposed land and sea. For a given CPF situation, when testing these predictions, understanding any constraints on foraging destinations (e.g. coastal breeding seabirds will be limited to foraging in open sea) will be important. Analyses of CPF flights in relation to wind may be helpful for understanding possibilities and limitations of the animals' responses to and exploitation of winds also in other flight situations, like long-distance migration, and for considering the consequences of local and global changes of wind regimes in animal movement ecology.

Acknowledgements We are grateful to Raymond Klaassen for stimulating discussions about wind and bird flight, and to Jared Wilson for comments on the manuscript. We are also grateful to two anonymous reviewers, particularly for pointing out the need to consider the effect of airspeed adjustment in relation to head-, tail- and crosswinds by one of them. This research did not receive any specific grants from funding agencies.

Open Access This article is distributed under the terms of the Creative Commons Attribution 4.0 International License (http://creativeco mmons.org/licenses/by/4.0/), which permits unrestricted use, distribution, and reproduction in any medium, provided you give appropriate credit to the original author(s) and the source, provide a link to the Creative Commons license, and indicate if changes were made.

\section{References}

Alerstam T (1979) Wind as selective agent in bird migration. Ornis Scand 10:76-93

Alerstam T (2000) Bird migration performance on the basis of flight mechanics and trigonometry. In: Domenici P, Blake RW (eds) Biomechanics in animal behaviour. BIOS Scientific, Oxford, pp $105-124$

Alerstam T (2011) Optimal bird migration revisited. J Ornithol 152(Suppl 1):S5-S23

Alerstam T, Gudmundsson GA, Larsson B (1993) Flight tracks and speeds of Antarctic and Atlantic seabirds: radar and optical measurements. Phil Trans R Soc Lond B 340:55-67 
Amélineau F, Péron C, Lescroël A, Authier M, Provost P, Grémillet D (2014) Windscape and tortuosity shape the flight costs of Northern Gannets. J Exp Biol 217:876-885

Chapman JW, Klaassen RHG, Drake VA, Fosette S, Hays GC, Metcalfe JD, Reynolds AM, Reynolds DR, Alerstam T (2011) Review: animal orientation strategies for movement in flows. Curr Biol 21:R861-R870

Elliott KH, Chivers LS, Bessey L, Gaston AJ, Hatch SA, Kato A, Osborne O, Ropert-Coudert Y, Speakman JR, Hare JF (2014) Windscapes shape seabird instantaneous energy costs but adult behavior buffers impact on offspring. Mov Ecol 2:17

Evans TJ, Kadin M, Olsson O, Åkesson S (2013) Foraging behaviour of Common Murres in the Baltic Sea, recorded by simultaneous attachment of GPS and time-depth recorder devices. Mar Ecol Prog Ser 475:277-289

Finn J, Carlsson J, Kelly T, Davenport J (2012) Avoidance of headwinds or exploitation of ground effect-why do birds fly low? J Field Ornithol 83:192-202

Furness RW, Bryant DM (1996) Effect of wind on field metabolic rates of breeding Northern Fulmars. Ecology 77:1181-1188

Gibb R, Shoji A, Fayet A, Perrins CM, Guilford TC, Guilford TC (2017) Remotely sensed wind speed predicts soaring behaviour in a wide-ranging pelagic seabird. J R Soc Interface 14:20170262

Glaumann M, Westerberg U (1988) Klimatplanering Vind. AB Svensk Byggtjänst, Stockholm (in Swedish)

Grémillet D, Dell'Omo G, Ryan PG, Peters G, Ropert-Coudert Y, Weeks SJ (2004) Offshore diplomacy, or how seabirds mitigate intra-specific competition: a case study based on GPS tracking of Cape Gannets from neighbouring colonies. Mar Ecol Prog Ser 268:265-279

Hedenström T, Alerstam T (1992) Climbing performance of migrating birds as a basis for estimating limits for fuel-carrying capacity and muscle work. J Exp Biol 164:19-38

Hedenström A, Alerstam T (1995) Optimal flight speed of birds. Phil Trans R Soc Lond B 348:471-487

Hedenström T, Alerstam T, Green M, Gudmundsson GA (2002) Adaptive variation of airspeed in relation to wind, altitude and climb rate by migrating birds in the Arctic. Behav Ecol Sociobiol 52:308-317

Hernández-Pliego J, Rodríguez C, Bustamante J (2014) Gone with the wind: seasonal trends in foraging movement direction for a central-place forager. Curr Zool 60:604-615

Houston AI (2006) The flight speed of birds feeding young. J Avian Biol 37:545-554

Howells R, Burthe S, Green J, Harris M, Newell M, Butler A, Johns D, Carnell E, Wanless S, Daunt F (2017) From days to decades: short- and long-term variation in environmental conditions affect offspring diet composition of a marine top predator. Mar Ecol Prog Ser 583:227-242

Johansson LC, Jakobsen L, Hedenström A (2018) Flight in ground effect dramatically reduces aerodynamic costs in bats. Curr Biol 28:3502-3507.e4

Karlsson H, Nilsson C, Bäckman J, Alerstam T (2012) Nocturnal passerine migrants fly faster in spring than in autumn: a test of the time minimization hypothesis. Anim Behav 83:87-93

Klein Heerenbrink M, Johansson LC, Hedenström A (2015) Power of the wingbeat: modelling the effects of flapping wings in vertebrate flight. Proc R Soc A 471. https://doi.org/10.1098/rspa.2014.0952

Klein Heerenbrink M, Warfvinge K, Hedenström A (2016) Wake analysis of aerodynamic components for the glide envelope of a Jackdaw (Corvus monedula). J Exp Biol 219:1572-1581

Liechti F (2006) Birds: blowin' by the wind? J Ornithol 147:202-211

Liechti F, Hedenström A, Alerstam T (1994) Effects of sidewinds on optimal flight speed of birds. J Theor Biol 170:219-225

McLaren J, Shamoun-Baranes J, Dokter AM, Klaassen R, Bouten W (2014) Optimal orientation in flows: providing a benchmark for animal movement strategies. J R Soc Interface 11:20140588
Norberg RÅ (1981) Optimal flight speeds in birds when feeding young. J Anim Ecol 50:473-477

Orians GH, Pearson NE (1979) On the theory of central place foraging. In: Horn DJ, Mitchell RD, Stairs GR (eds) Analysis of ecological systems. Ohio State University Press, Columbus, pp 154-177

Pennycuick CJ (1975) Mechanics of flight. In: Farner DS, King JR (eds) Avian biology, vol 5. Academic, New York, pp 1-75

Pennycuick CJ (1982) The flight of Petrels and Albatrosses (Procellariiformes), observed in South Georgia and its vicinity. Phil Trans R Soc Lond B 300:75-106

Pennycuick CJ (2002) Gust soaring as a basis for the flight of Petrels and Albatrosses (Procellariiformes). Avian Sci 2:1-12

Pennycuick CJ, Croxall JP, Prince PA (1984) Scaling of foraging radius and growth rate in Petrels and Albatrosses (Procellariiformes). Ornis Scand 15:145-154

Pennycuick CJ, Åkesson S, Hedenström A (2013) Air speeds of migrating birds observed by ornithodolite and compared with predictions from flight theory. J R Soc Interface 10:20130419

Raymond B, Shaffer SA, Sokolov S, Woehler EJ, Costa DP, Einoder L, Hindell M, Hosie G, Pinkerton M, Sagar PM, Scott D, Smith A, Thompson DR, Vertigan C, Weimerskirch H (2010) Shearwater foraging in the Southern Ocean: the roles of prey availability and winds. PLoS One 5:e10960

Rayner JMV (1991) On the aerodynamics of animal flight in ground effect. Phil Trans R Soc Lond B Biol Sci 334:119-128

Richardson PL (2011) How do Albatrosses fly around the world without flapping their wings? Prog Oceanogr 88:46-58

Richardson PL (2015) Upwind dynamic soaring of Albatrosses and UAVs. Prog Oceanogr 130:146-156

Riley JR, Reynolds DR, Smith AD, Edwards AS, Osborne JL, Williams IH, McCartney HA (1999) Compensation for wind drift by Bumble-Bees. Nature 400:126

Rose AP (2009) Temporal and individual variation in offspring provisioning by Tree Swallows: a new method of automated nest attendance monitoring. PLoS One 4:e4111

Sachs G (2016) In-flight measurement of upwind dynamic soaring in Albatrosses. Prog Oceanogr 142:47-57

Sapir N, Horvitz N, Dechmann DKN, Fahr J, Wikelski M (2014) Commuting Fruit Bats beneficially modulate their flight in relation to wind. Proc R Soc B 281:20140018

Schoener TW (1979) Generality of the size-distance relation in models of optimal feeding. Am Nat 114:902-914

Shamoun-Baranes J, Van Loon E, Liechti F, Bouten W (2007) Analyzing the effect of wind on flight: pitfalls and solutions. J Exp Biol 210:82-90

Spivey RJ, Stansfield S, Bishop CM (2014) Analysing the intermittent flapping flight of a Manx Shearwater, Puffinus puffinus, and its sporadic use of a wave-meandering wing-sailing flight strategy. Prog Oceanogr 125:62-73

Stephens DW, Krebs JR (1986) Foraging theory. Princeton University Press, Princeton

Sutton OG (1953) Micometeorology. McGraw Hill, New York

Wakefield ED, Phillips RA, Matthiopoulos J, Fukuda A, Higuchi H, Marshall GJ, Trathan PN (2009) Wind field and sex constrain the flight speeds of central-place foraging albatrosses. Ecol Monogr 79:663-679

Weimerskirch H, Guionnet T, Martin J, Shaffer SA, Costa DP (2000) Fast and fuel efficient? Optimal use of wind by flying Albatrosses. Proc R Soc Lond B 267:1869-1874

Weimerskirch H, Louzao M, de Grissac S, Delord K (2012) Changes in wind pattern alter Albatross distribution and life-history traits. Science 335:211-214

Publisher's Note Springer Nature remains neutral with regard to jurisdictional claims in published maps and institutional affiliations. 